Original Research Paper

\title{
The Extent of Community Awareness Using Natural Element's Instead of Using Chemical Drugs
}

\author{
Ilker Etikan, Ismail Bakır and Meliz Yuvalı \\ Department of Biostatistics, Near East University, Cyprus
}

Corresponding Author:

Ilker Etikan

Department of Biostatistics,

Faculty of Medicine, Near East

University, Nicosia-TRNC,

Cyprus

Email: ietikan@gmail.com

ilker.etikan@neu.edu.tr

\begin{abstract}
Alternative medicine it is a medicine that is not taught in traditional medicine. It is based on ancient historical foundations and different experiments in treatment without building it on the basis of scientific teacher. Alternative medicine is used in many peoples, especially non-developed peoples. Alternative medicine is used as primary medicine. The evidence of poor quality and knowledge about the awareness of using the natural drugs instead of using the chemical medication in the hospital. Little is known about the prevalence of natural medication in the Europe, especially in Cyprus. To determine the knowledge, community awareness, and to define the difference treatment practice between natural elements and chemical drugs. To identified the rate of the knowledge that students had and evaluate the results and measure it. Cross-sectional survey were performed by using SPSS and the Pearson Chi-Square test was done to determine the differences perform the questionnaire at near East University in Cyprus. We print our data as questionnaire paper and give it to 562 international students with different backgrounds. A total of 562 questionnaires were administered for this survey and the percentage respondents gender of students was $62.3 \%$ in males and $37,3 \%$ were females, also The Percentage of Respondents of students choose strongly disagree that were $47 \%$ and few of students shown $6.1 \%$ Percentage in strongly disagree. Furthermore, student's percentage of that prefer use of natural elements that were $66.5 \%$ cheaper with strongly agree, $21.2 \%$ with agree, $2.8 \%$ with strongly disagree, and disagree that were $9.5 \%$. Furthermore, students $38.0 \%$ Yoga with good scale, 35.2\% Herbal with good scale and $34.6 \%$ Holy books with excellent scale. (Respectively, $\mathrm{p}<0.05)$. Students who students that were in cheaper scale chosen the natural elements treatment $30.8 \%$ just for poor, $33.8 \%$. Just for rich and for everyone $31.9 \%$.it also shows that interactions between natural elements and chemical drugs that found $50.5 \%$ of students, $44.1 \%$ and sometimes $43.4 \%$. (Respectively, $\mathrm{p}<0.05$ ). The doctors can play a crucial role to increase the awareness of clients, Educational continues can be used to highlight the role of increases awareness for students in drug-related problems. The use of Complementary and Alternative Medicine (CAM) appears to be low in the general student in Near East University.
\end{abstract}

Keywords: Near East University, Natural Element's, Chemical Drugs

\section{Introduction}

Community Awareness is a term that used to describe both the minimization of negative impacts and positive community understanding in the Extent of Community awareness using the natural element's instead of using chemical drugs. Community awareness often refers to the degree that some population generally know about using the natural drug instead of chemical drugs, about social norms and people's different roles within the community and about issues that affect the community in using both chemical and natural drugs (Syed et al., 2013).

There has been a global rise in the use of natural health products. Proper regulation of natural drugs is 
pivotal to ensure good quality control standards, enhance consumers' safety and facilitate their integration into modern healthcare systems. Moreover, this designed to determine awareness, patterns of use, general attitude and information requirements about natural drugs instead of chemical drugs among the public.

The widespread use of natural drug around the world requires health professionals including pharmacists to have the required knowledge to better advise their patients. This has led to an increased need for the inclusion of natural drugs instruction into the mainstream Pharmacy education. This study was designed to describe student's awareness, use, attitude and perceived need for natural drugs instead of using chemical education at near east university and at the same time, determine how these descriptive outcomes are influenced by the socio-demographic variables considered in the study.

The study conducted at the near east university in Cyprus. The university have more than 30 specialization on certain bachelor degree and master and $\mathrm{PhD}$. This questionnaire will summarized the replies gathered. Key statistics will be provided as SPSS calculations. Although they should be taken within the context of all replies, provided in the study. All Demographic Data were also collected, and at times examples with be given in the text, reproduced exactly as written.

The purpose of the questionnaire is to determine the efficiency of natural medication safety education on perceptions of the awareness, knowledge and practices of education students in the university.

The questionnaire was 25 questions applied and giving to the students in the near east university campus. Of the 25 replies received, the answers provide interesting reading. Overall, the responses have been positive, with SPSS finding the resources and opportunities presented to be valuable assets. The work of the all gathering answered was also highly commended. In all campus, however, there were suggestions for improvements. Given this, it is important for the questionnaire to take the statistical analysis alongside the data, to provide us accurate overview.

Next, were asked a series of questions relating to the Extent of Community awareness using the natural element's instead of using chemical drugs. A summary of responses is provided next. Reassuringly, no one thought that the natural drugs are of no use and almost all believe it to may cause side effect or hurt the human system. A similarly high rate was recorded for the frequency of the research. The answers for the relevance of information and language level dropped a little.

The Extent of Community awareness using the natural element's instead of using chemical drugs is considered as a serious global public health issue. In recent years, countries have increasingly recognized the importance of improving drugs safety. Medication is a significant issue affecting patient health in both ways good or bad. And costs in hospitals often posturing dangerous consequences for patients. Little is known about the prevalence of natural medication in Cyprus, especially in the near east university hospital. Proper understanding of the community awareness using the natural drugs. Investigating student's perception in university campus of these natural elements and outlining what barriers lay behind reporting these alternative and performing educational questionnaire to improve the practices could be the cutting edge between patients' safety and using these natural drugs.

The evidence of poor quality and knowledge about the awareness of using the natural drugs instead of using the chemical medication in the hospital. Little is known about the prevalence of natural medication in the Europe, especially in Cyprus (Akan et al., 2012; Syed et al., 2013).

The interventional, student's group pretest/posttest study will be designed to evaluate the effectiveness of the questionnaire to improve the Perception, Knowledge and Practices of the Extent of Community awareness using.

The natural element's instead of using chemical drugs of the students who's study near east university in Cyprus.

The Secretariat is always keen to gather opinions about its performance, in order to improve its efficiency and usefulness. The questionnaires have provided an overview of different viewpoints, and raised some issues and suggestions that the Secretariat will try to take on board. It would appear that the general feeling among is that the Secretariat is doing its job well and producing valuable resources. The ideas for changes that have been raised, however, will prevent the Secretariat from becoming complacent and ensure that fresh approaches and innovative methods will be attempted whenever realistically possible (Andreatini et al., 2002).

Some students give the impression that their authors tried to think of every conceivable question that might be asked with respect to the general topic of concern. Alternatively, a committee may have incorporated all of the questions generated by its members. Stringent efforts should be made to avoid such shotgun approaches, because they tend to yield very long questionnaires often with many questions relevant to only small proportions of the sample. The result is annoyance and frustration on the part of many responders. They resent the time it takes to answer and are likely to feel their responses are unimportant if many of the questions are inapplicable. Their annoyance and frustration then causes non-return of mailed questionnaires and incomplete or inaccurate responses on questionnaires administered directly. These 
difficulties can yield largely useless results. Avoiding them is relatively simple but does require some time and effort.

We will observe the elements of the Extent of Community awareness using the natural element's instead of using chemical drugs (observational study to evaluate the adherence the information that students know about the topic) (Ernst, 2002).

\section{Methods}

\section{Study Design}

The nursing master students in health faculty during study Nursing Research course they are prepared survey for The Extent of Community awareness using the natural element's instead of using chemical drugs Survey. This is a cross-sectional survey design was used to get and achieve the set objectives. The aim of our study is to determine the knowledge, community awareness, and to define the difference treatment practice between natural element's and chemical drugs.

\section{Study Site}

The study was conducted in March 2017 at the Near East University, Nicosia North Cyprus. The Near East University offered undergraduate and postgraduate education opportunities for local and international students.

Also each questionnaire was answered through fifteen minutes

\section{Data Collection}

The questionnaire consisted of 2 sections of 21 multiple choice questions and 4 close-ended questions assessing knowledge, community awareness between natural element's and chemical drugs for international students. The information obtained from the questionnaire included the demographics of responders such as (Age, Gender, Nationality, Level of education, Religion, Marital status), assess impression of using natural elements, knowledge drugs culture and information's and determined the natural element's and chemical drugs awareness. The scale uses of 21 multiple choice questions were (Always, Sometimes, Scarcely, Never, Strongly agree, Agree, Strongly disagree). Also the most questions answers was deceptive scale.

\section{Study Population (Including Inclusion and Exclusion Criteria)}

The study was organized on the international students in the Near East University. The study included all students who agree to answer the questionnaire and excluded the students who refused to answer it because some of them are busy, others ignoring the subject and other reasons.

\section{Sampling Method and Hypothesis}

A total of 562 participants from the Near East University were selected for the study using appropriate sampling method:

1. Assess impression and feedback of participants when using natural elements and complementary medicine for treatment

2. Assess knowledge and main source of drugs and treatment

3. Explain and find the main reason while natural elements and complementary medicine. the participants prefer using

4. To perform and evaluate the outcome natural elements when the participants use

5. To assess and crate the reasons for the participants choose the natural elements durıng treatment process and to this treatment get the target group choose

6. To check the motivations and affecting natural elements participants when they use

7. To evaluate awareness and kind of treatment the participants preferred to deal his illness

8. To check the previous history knowledge and information's about natural elements before used and main side effect

\section{Data Analysis}

Statistical Package of Social Sciences (SPSS) software version 20.0 was used to analyze the collected data. The methods used to analyze the data include an analysis of descriptive statistic variables such as frequency and percentages for the categorical variables. The Pearson Chi-Square test was done to determine the differences. When F statistic was significant, the chosen level of significance is $\mathrm{p}<0.05$.

\section{Results}

A total of 562 questionnaires were administered for this survey and the percentage respondents gender of students was $62.3 \%$ in males and $37,3 \%$ were females also the number student was in our study is Male 350 , females 212 . About $70.8 \%$ of students were in the BA, $20,1 \%$ were in the Master students, and $9,1 \%$ were in the PHD students. A majority of students $48.8 \%$ were christen, 43, 4\% that were Muslim and 8,2\% were other religion, a total of students that were single (78,6\%), 17,6\% that they married, and 3,7\% in relationship Table 1.

According to the outcome result it were five category of sources of drugs and treatment compared with gender, Nurse it was higher percentage (69.7\%) in male students; Friend and internet come second $(66.7 \%)$, the third category was attar it was percentage (64.3\%); doctor come fourth $(60.3 \%)$; and the last category that were 
pharmacist in percentage $(60.3 \%)$, While the result of females students, the pharmacist it was higher percentage (39.7\%), doctor, attar, then Friend and internet and the last one it was nurse.

According to result of Table 2 the highest percentage that were in BA students $(78.3 \%)$ in excellent scale about impression of using natural elements, Also the PHD students that shown lowest scale it was (6.1) and 13 out of 562 (Respectively, $\mathrm{p}>0.05$ ).

A total of $(48.0 \%, 48.4 \%, 47.9 \%, 48.4 \%)$ Christen students shows that had use a different kind of natural elements therapy more than Muslims students especially in Holy books that were $(44.9 \%)$, and few student of others religions is shown not too much use different kind of natural elements (Respectively, $\mathrm{p}<0.05$ ) Table 3.

The Percentage Respondents of students choose strongly disagree that were $47.0 \%$ when we compared between of impression of using natural elements and used better than drugs; the result was few of students shown (6.1\%) Percentage in strongly disagree, (Respectively, $\mathrm{p}<0.05$ ) Table 4.

Total of students that were in always scale ask doctor to give you drugs and treatment and taken a drug without a prescription it was $(21.5 \%)$, percentage of sometime $41.4 \%$, scarcely $17.8 \%$ and never $19.3 \%$ (Respectively, $\mathrm{p}<0.05$ ) Table 5 .

According for Table 6 that found the students percentage of that prefer use of natural elements that were $66.5 \%$ cheaper with strongly agree, $21.2 \%$ with agree, $2.8 \%$ with strongly disagree, and disagree that were $9.5 \%$ (Respectively, $\mathrm{p}>0.05$ ).

According for Table 7 that found the students percentage of that natural elements treatment outcome during use different kind of natural elements that shown $38.0 \%$ Yoga with good scale, 35.2\% Herbal with good scale and $34.6 \%$ Holy books with excellent scale (Respectively, $\mathrm{p}<0.05$ ).

Total of students that were in cheaper scale chosen the natural elements treatment $30.8 \%$ just for poor,
$33.8 \%$. Just for rich and for everyone $31.9 \%$. Moreover, Safe Side Effect percentage it was for rich $32,5 \%$, $31,9 \%$ for everyone and the last percentage that were $29.1 \%$ in poor scale (Respectively, $\mathrm{p}<0.05$ ) Table 8 .

The Percentage Respondents of students to deal with medicinal herbs and medicines manufactured and prefer to deal it that found highest of student prefer deal with medicinal herbs with percentages in cheaper $38.0 \%$, Safe Side Effect 40.6\%, Natural Origin 43.1\% and The Most Powerful Influence $35.4 \%$ (Respectively, $\mathrm{p}<0.05$ ) Table 9.

According for Table 10 to get information about the natural elements before using and affection for slimming and weight loss the percentages that were $51.4 \%$ affecting and $59.8 \%$ un-affecting and $41.5 \%$ it was in I don't know (Respectively, $\mathrm{p}>0.05$ ).

According for Table 11 to get information about the natural elements before using and interactions between natural elements and chemical drugs that found $50.5 \%$ of students, $44.1 \%$ and sometimes $43.4 \%$ (Respectively, $\mathrm{p}<0.05$ ).

The percentage respondents of students a centers for treating with natural elements and dangerous of natural elements the almost of students they were (50.0\%) strongly agree dangerous, $51.4 \%$ Agree, $49.3 \%$ strongly Disagree and finally disagree that were $43.9 \%$ (Respectively, $\mathrm{p}<0.05$ ) Table 12.

Table 13 shown percentage of how long natural elements used of student's country with specialist person, which found used $78.9 \%$ have license, 52.3\% without license and 49.3\% I don't know. Also according to the student who partly used that were $13.6 \%$ have license, $20.3 \%$ without license and I don't know it was $35.1 \%$ (Respectively, $\mathrm{p}>0.05$ ).

Table 14 shown percentage prefer using natural elements with specialist person, that found the highest score in safe side effect with have license $36.7 \%$, natural origin $27.9 \%$, cheaper $27.2 \%$ and the final score that were the most powerful influence $8.2 \%$ (Respectively, $\mathrm{p}>0.05$ ).

Table 1: Demographic data

\begin{tabular}{lll}
\hline Characteristics & $(\mathrm{n}=562)$ & Percentage respondents $\%$ \\
\hline Gender & 350 & $62.3 \%$ \\
Male & 212 & $37,3 \%$ \\
Female & & \\
Level of education & 398 & $70.8 \%$ \\
BA & 113 & $20,1 \%$ \\
Master & 51 & $9,1 \%$ \\
PHD & & $48,8 \%$ \\
Religion & 272 & $43,4 \%$ \\
Christen & 244 & $8,2 \%$ \\
Muslim & 46 & $78,6 \%$ \\
Others & & $17,6 \%$ \\
Marital status & 442 & $3,7 \%$ \\
Single & 99 & \\
Married & 21 & \\
Relationship & & \\
\hline
\end{tabular}


Ilker Etikan et al. / Current Research in Biostatistics 2017, 7 (2): 30.38

DOI: 10.3844/amjbsp.2017.30.38

Table 2: Compared between levels of education with impression of using natural elements

\begin{tabular}{llllll}
\hline Level of education & Excellent & Good & Acceptable & Bad & I do not know \\
\hline BA & $78.3 \%$ & $68.4 \%$ & $65.6 \%$ & $72.2 \%$ & $50.0 \%$ \\
MS & $15.6 \%$ & $20.3 \%$ & $28.0 \%$ & $19.4 \%$ & $26.5 \%$ \\
PHD & $6.1 \%$ & $11.2 \%$ & $6.5 \%$ & $8.3 \%$ & $23.5 \%$ \\
\hline
\end{tabular}

Table 3: Compared between religion with kind of natural elements therapy

\begin{tabular}{lllll}
\hline Religion & Holy books & Herbal & Yoga & Massage \\
\hline Christen & 48.0 & 48.4 & 47.9 & 48.4 \\
Muslims & 44.9 & 43.9 & 43.7 & 43.4 \\
Others & 7.1 & 7.7 & 8.5 & 8.2 \\
\hline
\end{tabular}

Table 4: Compared between of impression of using natural elements and used better than drugs

\begin{tabular}{lcccc}
\hline & Strongly agree & Agree & Strongly disagree & Disagree \\
\hline Excellent & $37.2 \%$ & $37.4 \%$ & $47.0 \%$ & $32.1 \%$ \\
Good & $29.8 \%$ & $35.7 \%$ & $30.3 \%$ & $32.1 \%$ \\
Acceptable & $18.2 \%$ & $15.3 \%$ & $12.1 \%$ & $22.2 \%$ \\
Bad & $9.1 \%$ & $5.8 \%$ & $4.5 \%$ & $6.2 \%$ \\
I don't know & $5.8 \%$ & $5.8 \%$ & $6.1 \%$ & $7.4 \%$ \\
\hline
\end{tabular}

Table 5: Compared between source of drugs with taken drug without a prescription

\begin{tabular}{llllrr}
\hline & Doctor & Pharmacist & Nurse & Attar & Friend \\
\hline Always & $21.5 \%$ & $17.5 \%$ & $27.3 \%$ & $35.7 \%$ & $19.4 \%$ \\
Sometime & $41.4 \%$ & $39.7 \%$ & $33.3 \%$ & $42.9 \%$ & $38.9 \%$ \\
Scarcely & $17.8 \%$ & $16.7 \%$ & $12.1 \%$ & $7.1 \%$ & $16.7 \%$ \\
Never & $19.3 \%$ & $26.2 \%$ & $27.3 \%$ & $14.3 \%$ & $25.0 \%$ \\
\hline
\end{tabular}

Table 6: Compared between use of complementary Medicine is better than drugs with prefer using natural elements

\begin{tabular}{lcccc}
\hline & Cheaper & Safe side effect & Natural origin & The most powerful influence \\
\hline Strongly Agree & $66.5 \%$ & $0.0 \%$ & $0.6 \%$ & $2.1 \%$ \\
Agree & $21.2 \%$ & $98.9 \%$ & $39.4 \%$ & $41.7 \%$ \\
Strongly Disagree & $2.8 \%$ & $1.1 \%$ & $33.8 \%$ & $10.4 \%$ \\
Disagree & $9.5 \%$ & $0.0 \%$ & $26.3 \%$ & $45.8 \%$ \\
\hline
\end{tabular}

Table 7: Compered between natural elements treatment outcome during use different kind of natural elements

\begin{tabular}{lcrrr}
\hline & Holy books & Herbal & Yoga & Massage \\
\hline Excellent & $34.6 \%$ & $30.0 \%$ & $26.8 \%$ & $32.5 \%$ \\
Good & $26.0 \%$ & $35.2 \%$ & $38.0 \%$ & $31.2 \%$ \\
Acceptable & $27.6 \%$ & $26.8 \%$ & $23.9 \%$ & $31.2 \%$ \\
Bad & $10.2 \%$ & $5.6 \%$ & $7.0 \%$ & $3.9 \%$ \\
I don't know & $1.6 \%$ & $2.4 \%$ & $4.2 \%$ & $1.3 \%$ \\
\hline
\end{tabular}

Table 8: Compered between prefer using natural elements with natural element for poor or rich people

\begin{tabular}{lccc}
\hline & Just for poor & Just for rich & For everyone \\
\hline Cheaper & $30.8 \%$ & $33.8 \%$ & $31.9 \%$ \\
Safe side effect & $29.1 \%$ & $32.5 \%$ & $31.9 \%$ \\
Natural origin & $31.4 \%$ & $31.2 \%$ & $26.2 \%$ \\
The most powerful influence & $8.7 \%$ & $2.6 \%$ & $9.9 \%$ \\
\hline
\end{tabular}

Table 9: Compered between deal with medicinal herbs and medicines manufactured and causes prefer medicinal herbs

\begin{tabular}{lllll}
\hline & Cheaper & Safe side effect & Natural origin & The most powerful influence \\
\hline Medicinal herbs & $38.0 \%$ & $40.6 \%$ & $43.1 \%$ & $35.4 \%$ \\
Medicinal manufactured & $36.9 \%$ & $33.1 \%$ & $40.0 \%$ & $31.3 \%$ \\
I do not care & $25.1 \%$ & $26.3 \%$ & $16.9 \%$ & $33.3 \%$ \\
\hline
\end{tabular}

Table 10: Get information about the natural elements before using and affection for slimming and weight loss

\begin{tabular}{llll}
\hline & YES & NO & Sometimes \\
\hline YES & $51.4 \%$ & $18.9 \%$ & $23.6 \%$ \\
NO & $28.3 \%$ & $59.8 \%$ & $34.9 \%$ \\
I don't know & $20.4 \%$ & $21.3 \%$ & $41.5 \%$ \\
\hline
\end{tabular}


Table 11: Get information about the natural elements between natural elements and chemical drugs before using and interactions

\begin{tabular}{llll}
\hline & YES & NO & Sometimes \\
\hline YES & $50.5 \%$ & $44.1 \%$ & $43.4 \%$ \\
NO & $25.8 \%$ & $22.0 \%$ & $28.3 \%$ \\
Sometimes & $16.1 \%$ & $18.9 \%$ & $17.0 \%$ \\
I don't know & $7.6 \%$ & $15.0 \%$ & $11.3 \%$ \\
\hline
\end{tabular}

Table 12: Centers for treating with natural elements and dangerous of natural elements

\begin{tabular}{lllll}
\hline & Strongly agree & Agree & Strongly disagree & Disagree \\
\hline YES & $50.0 \%$ & $51.4 \%$ & $49.3 \%$ & $43.9 \%$ \\
NO & $32.0 \%$ & $28.3 \%$ & $25.4 \%$ & $39.4 \%$ \\
I don't know & $18.0 \%$ & $20.2 \%$ & $25.4 \%$ & $16.7 \%$ \\
\hline
\end{tabular}

Table 13: How long natural elements used of student's country with specialist person

\begin{tabular}{llll}
\hline & Have license & Without license & I don't know \\
\hline Used & $78.9 \%$ & $52.3 \%$ & $49.3 \%$ \\
Unused & $7.5 \%$ & $27.4 \%$ & $15.7 \%$ \\
Partly used & $13.6 \%$ & $20.3 \%$ & $35.1 \%$ \\
\hline
\end{tabular}

Table 14: Compered between prefer using natural elements with specialist person

\begin{tabular}{llll}
\hline & Have license & Without license & I don't know \\
\hline Cheaper & $27.2 \%$ & $33.5 \%$ & $33.6 \%$ \\
Safe side effect & $36.7 \%$ & $26.7 \%$ & $34.3 \%$ \\
Natural origin & $27.9 \%$ & $32.7 \%$ & $20.1 \%$ \\
The most powerful influence & $8.2 \%$ & $7.1 \%$ & $11.9 \%$ \\
\hline
\end{tabular}

Table 15: Affecting using of natural elements and category age of natural elements

\begin{tabular}{llll}
\hline & Old ages & Middle ages & Young ages \\
\hline Yes & $37.7 \%$ & $43.0 \%$ & $39.3 \%$ \\
No & $37.1 \%$ & $34.7 \%$ & $39.3 \%$ \\
I don't know & $25.2 \%$ & $22.3 \%$ & $21.4 \%$ \\
\hline
\end{tabular}

According for Table 15 that shown affecting using of natural elements and category age of natural elements that were old ages with affecting (37.7\%), 37.1\% without affecting, 25.2\% I don't know. The second category is middle ages that were $43.0 \%$ with affecting and Young ages it was 39.3\% (Respectively, $\mathrm{p}<0.05$ ).

\section{Discussion}

A total of 562 questionnaires were administered for this survey and the percentage respondents gender of students was $62.3 \%$ in males and $37,3 \%$ were females. About $70.8 \%$ of students were in the BA, $20,1 \%$ were in the Master students and 9,1\% were in the PHD. students. A majority of students $48.8 \%$ were christen, $43,4 \%$ that were Muslim and $8,2 \%$ were other religion, a total of students that were single $(78,6 \%), 17,6 \%$ that they married and 3,7\% in relationship Table 16.

According to the demographic table, the results will describe male awareness more than female awareness due to the high male participants in the survey. Since the majority of the participants were in the level of undergraduate students so the extend of the awareness according the outcome of the result supposed to aid BA level of education. Religion a variable can be considered neutral because of the similar participants from the two main religion. Marital status does not effect on any outcome.

The purpose of our study is to evaluate the level of knowledge, community awareness and define the difference treatment practice between natural element's and chemical drugs among international students inside near east university campus. There has been a considerable increase in the worldwide use and proliferation of herbal medicines. Medicinal herbs now constitute the most rapidly growing segment of the U.S (Ernst, 2002). alternative medicine market, in the survey we found the result show students that deal with medicinal herbs highest of student prefer deal with Medicinal manufactured so medicinal herbs as this survey appear that it have more preferable for students its show high percentages in cheaper $38.0 \%$, Safe Side Effect $40.6 \%$, Natural Origin $43.1 \%$ and The Most Powerful Influence $35.4 \%$ than Medicinal manufactured, this result show similar as that the level of knowledge and awareness of student from using natural elements is high as shown in our survey (Syed et al., 2013).

According to the result that is shown in Table 17. Which generally shows awareness of students in selecting the right source to get drug and treatments. Doctors are the main source that international students 
refer to them to get drug and treatment when they need it. The result shows that the international students are aware of choosing the right person in case if they are ill. 22.4\% of the students are referring to pharmacist to get drug and treatment in those cases the pharmacist supposes to be aware of the client health condition. It is clear that majority of them are not aware that pharmacist and nurse are the source that can be asked to get information about drug-related problems. The doctors can play a crucial role to increase the awareness of clients about pharmacist since the pharmacist is a person that supposed to have knowledge about drugs. Educational workshops can be used to highlight the role of pharmacist in drug-related problems. A study made by Westerlund et al. (1999) supported that the improvement in pharmacy practice leads to better understanding between the customer and the pharmacist in illness detection, drug-related and drugdrug interaction problems.

Table 18 represent the relation between religion and type of natural treatments that they prefer. Among international students based on their religiosity for the different type of treatments, Herbal is the one that $51.1 \%$ of participants prefer it. It is important to notice that using right herbal to treat an illness can be effective due to the nature of the herbals that contain some elements that are the main sources for chemical drugs.

According to the study that made by Sloan et al. (1999) on effect of religion and spiritual activities on person comfort ability, most of the people felt comfort in case of illness by using religious activities. $22.6 \%$ of total participants in this study believe that Holy book can be used as treatment of some illnesses but there is not a scientific reason behind it. As it has been stated in previous study there is still research on the effect of religious activities in US medical schools (Sloan et al., 1999). In relating to community awareness, people should not be encouraged to use Holy books as a natural element for treatments, but some researchers (Mueller et al., 2001) they believed that more study should be done due to the fact that in most of the surveys majority of participants accept religious activities as treatment.

According to Koenig (2000) nearly 350 physical and 850 mentally health problems by involvement of religious treatment the better health outcome was recorded. The religion leaderships (Imam, Priest, Others) should be aware of natural element therapies and encourage people in the right way to extent the awareness of community.

Table 16: Demographic data

\begin{tabular}{lll}
\hline Characteristics & $(\mathrm{n}=562)$ & Percentage respondents $\%$ \\
\hline Gender & & $62.3 \%$ \\
Male & 350 & $37,3 \%$ \\
Female & 212 & $70.8 \%$ \\
Level of education & & $20,1 \%$ \\
BA & 398 & $9,1 \%$ \\
Master & 113 & $48,8 \%$ \\
PHD & 51 & $43,4 \%$ \\
Religion & & $8,2 \%$ \\
Christen & 272 & $78,6 \%$ \\
Muslim & 244 & $17,6 \%$ \\
Others & 46 & $3,7 \%$ \\
Marital status & & \\
Single & 442 & \\
Married & 99 & \\
Relationship & 21 & \\
& &
\end{tabular}

Table 17: Selection of a source for getting drug and treatment with respect to gender

\begin{tabular}{|c|c|c|c|c|c|}
\hline & Doctor & Pharmacist & Nurse & Attar & Friend and internet \\
\hline \multicolumn{6}{|l|}{$\overline{\text { Gender }}$} \\
\hline Male & $62.3 \%$ & $21.7 \%$ & $6.6 \%$ & $2.6 \%$ & $6.9 \%$ \\
\hline Female & $63.7 \%$ & $23.6 \%$ & $4.7 \%$ & $2.4 \%$ & $5.7 \%$ \\
\hline Total & $62.8 \%$ & $22.4 \%$ & $5.9 \%$ & $2.5 \%$ & $6.4 \%$ \\
\hline
\end{tabular}

Table 18: Compared between religion with kind of natural elements therapy

\begin{tabular}{llccc}
\hline Religion & Holy books & Herbal & Yoga & Massage \\
\hline Christen & $22.4 \%$ & $51.1 \%$ & $12.5 \%$ & $14 \%$ \\
Muslims & $23.4 \%$ & $51.6 \%$ & $12.7 \%$ & $12.3 \%$ \\
Others & $19.6 \%$ & $47.8 \%$ & $13.0 \%$ & $19.6 \%$ \\
Total & $22.6 \%$ & $51.1 \%$ & $12.6 \%$ & $13.7 \%$ \\
\hline
\end{tabular}


Also within collecting our findings data to measure our international student level of knowledge and community awareness about try to get information about the natural elements before using and interactions between natural elements and chemical drugs we found that the percentage $50.5 \%$ of students were have importance in searching about the neutral element before using it comparing of percentage $44.1 \%$ of students that don't mind to get information before using, which indicating that the awareness is high Within our university students.

Medication can help many people who suffer from a disease to live longer, healthier lives. For medication to have the desired result, it should be taken as prescribed (Tan et al., 2004). However, far too often people do not take their medication properly. we found in our survey that students show they are follow doctor prescribe about $62.8 \%$ of all male and female gender among students; this percentage indicate that students have a high awareness in treatment their illness without taking advice from non-accredited source; so this result reflected this study that Non-adherence can be expressed indifferent ways, but international student show a high percentage for following medical orders so this be a good point of their attitudes of good background in adherence of talking right type of medication ether natural elements treatment or chemical drugs.

Nowadays the use of herbal weight loss products as alternative obesity treatment has increased, which leads to the growing market of herbal remedies worldwide (Bodeker and Kronenberg, 2002). Which this result reflex what we want to assess from our international student about their thought of affection for slimming and weight loss by using natural elements which it shows $51.4 \%$ that student agree with the benefits of natural element in diet and important role in weight loss, this show that the effectiveness of natural component is safe on human body.

\section{Conclusion}

Alternative medicine depends on the exact examination of the patient, in addition to his physical condition, taking into account his mental and mental state as well. Also Alternative medicine works to treat the patient by looking at him as an integral and interrelated body, body and mind and by stimulating his mental and physical abilities and trying to treat him in various therapeutic ways available. There are many other methods of treatment that rely on natural means and methods away from the tools of modern medicine, which may fail in the treatment of some patients, becomes their only solution is to return to nature.

Complementary medicine if used correctly and scientifically, the results are distinctive, especially if several methods of treatment are used with each other and according to the patient's condition and this in itself requires a great experience from the therapist until the best treatment methods are used. It should be noted that complementary medicine has begun to spread widely and has begun to study in many countries of the world, but must adhere to the methodology and professionalism in the use of complementary medicine

However, Complementary medicine cannot treat all the diseases because there is no absolute medicine, but it is used to treat a variety of diseases that provide accurate diagnosis of the first catalyst, which is the cause of the disease, not the symptoms that depend only on The success of this medicine over the past few years in the treatment of a variety of diseases and record the patient's health performance is excellent, but you should pay attention to the place? So, what? These techniques provide, instead of focusing on false allegations, this type of treatment, especially these models in the supplemental medical treatment produces negative other and remains the most important subject medical conscience in all kinds of medicine.

\section{Acknowledgement}

We would like to thank the students of Near East University who volunteered for our surveys in this research.

\section{Author's Contributions}

All authors equally contributed in this work.

\section{Ethics}

This study was conducted on students within the University. Since there was no invasive procedure, the ethics committee was not consulted but only with permission from the university administration. The study is a cross-sectional study, with the aim of determining the level of knowledge.

\section{References}

Akan, H., G. Izbirak, E.Ç. Kaspar, Ç.A. Kaya and S. Aydin et al., 2012. Knowledge and attitudes towards complementary and alternative medicine among medical students in Turkey. BMC Complementary Alternative Med., 12: 1-7.

DOI: $10.1186 / 1472-6882-12-115$

Andreatini, R., V.A. Sartori, M.L.V. Seabra and J.R. Leite, 2002. Effect of valepotriates (valerian extract) in generalized anxiety disorder: A randomized placebo-controlled pilot study. Phytother. Res., 16: 650-654.

Bodeker, G. and F. Kronenberg, 2002. A public health agenda for traditional, complementary and alternative medicine. Am. J. Public Health, 92: 1582-1591. 
Ernst, E., 2002. Adulteration of chinese herbal medicines with synthetic drugs: a systematic review. J. Internal Med., 252: 107-113.

Koenig, H.G., 2000. Religion, spirituality and medicine: Application to clinical practice. Jama, 284: 1708-1708. DOI: 10.1001/jama.284.13.1708-JMS1004-5-1

Mueller, P.S., D.J. Plevak and T.A. Rummans, 2001. Religious involvement, spirituality and medicine: implications for clinical practice. Mayo Clinic Proceed., 76: 1225-1235.

Sloan, R.P., E. Bagiella and T. Powell, 1999. Religion, spirituality and medicine. Lancet, 353: 664-667. DOI: $10.1016 / \mathrm{S} 0140-6736(98) 07376-0$
Syed, N., M. Naseer, M.Q. Memon and K. Rani, 2013. Prevalence of self-medication and its practice among the medical and non-medical students. Liaquat University of Medical and Health Sciences.

Tan, M., O. Uzun and F. Akçay, 2004. Trends in complementary and alternative medicine in eastern Turkey. J. Alternative Complementary Med., 10: 861-865. DOI: 10.1089/acm.2004.10.861

Westerlund, T., A.B. Almarsdóttir and A. Melander, 1999. Drug_related problems and pharmacy interventions in community practice. Int. J. Pharmacy Pract., 7: 40-50.

DOI: 10.1111/j.2042-7174.1999.tb00947.x 